\title{
Study on Quality Evaluation System for University Students
}

\author{
He Yongqiang, ${ }^{\mathrm{a}}$ Yang Mingming \\ ${ }^{a}$ Henan Institute of Engineering, Zhengzhou, China \\ ${ }^{b}$ Henan Institute of Engineering, Zhengzhou, China
}

\begin{abstract}
From the qualitative and quantitative perspectives, by use of modern educational philosophy and statistics evaluation theory, this thesis makes study on the theory for university students' comprehensive quality evaluation. It makes careful analysis on the students' daily life according to their characters, and makes scientific classification after picking up the main aspects, and then, combining the design principle of indictor system and hierarchic method, it establishes scientific and reasonable comprehensive quality evaluation indicator system for university students, which is easy to operate and meets the demand of the age. So the system can measure and evaluate the comprehensive quality of university students in a more scientific and objective way. Meanwhile, this thesis puts forward effective methods for university students' comprehensive quality evaluation under new situations.
\end{abstract}

Index Terms: university students; comprehensive quality; evaluation system; design principle; methods

(C) 2011 Published by MECS Publisher. Selection and/or peer review under responsibility of the Research Association of Modern Education and Computer Science

\section{Introduction}

University students' comprehensive quality evaluation is one of the most basic filed of educational evaluation, which plays a pivot role in it. By quality evaluation, it means the process of collecting the representation information of the evaluation object in main activity areas by use of scientific method, and then judging one certain quality according to the evaluation goal. In other words, it is an activity to evaluate talents' qualities comprehensively through various means of evaluation, judgment and examination. It aims to identify and assess quality of the evaluation object, which consists of evaluation process and outcome evaluation.

Contemporary tertiary education of our country attaches importance to quality-oriented education, so the basic requirements of it should be the starting point of university students' comprehensive quality evaluation. The traditional university students' comprehensive evaluation system, as a relatively effective evaluation and motivating method, plays a good role as guide and evaluation method in students' education. However, with the gradual advance of quality-oriented education in institutions of higher learning, the educational circles are fully aware of that the traditional evaluation system is not developing in a way suited to the value of quality-oriented

The key scientific and technological project of the Education Department of Henan Province.

* Corresponding author.

E-mail address: ${ }^{\mathrm{a}}$ yqhe18@163.com; ${ }^{\mathrm{b}}$ ym@haue.edu.cn 
education and educational concept. It has been the top priority mutually concerned by each institution of high learning and educational research institutes that how to effectively carry out and implement the quality-oriented education and build the scientific comprehensive evaluation system with relatively strong fairness, operability and practicability in order to evaluate university students' comprehensive quality objectively.

\section{Existing Problems of the Current University Students’ Comprehensive Quality Evaluation}

\subsection{Orientation Function of Quality Evaluation is not Distinct}

The existing comprehensive evaluation system can reflect true situations of a student basically, but value orientation of some comprehensive evaluation system is not that distinct. Evaluation value orientation must fit requirements for university students by the age. However, in actual operation, professional competence accounts for a large proportion, while humanities quality, scientific quality and innovative ability account for a small proportion. Thus comprehensive evaluation still doesn't overcome the barriers of "exam-oriented education", so it generates a wrong value orientation for students, which makes them place undue emphasis on the high scores and ignore cultivation and improvement of self comprehensive quality, so the students educated under this condition cannot meet the demand of the age and social development.

\subsection{Weak Combination of Qualitative Analysis and Quantitative Analysis of Quality Evaluation}

Quality evaluation is complicated, for it is difficult to quantify the following factors, including thought, emotion, sensibility, tastes and attitude. So, combination of qualitative analysis and quantitative analysis is not enough, which cannot effectively meet the demand of quality evaluation. Quality evaluation should gradually develop from qualitative to quantitative. By use of experimental design, it will quantify evaluation as much as possible. New research methods should be introduced successively during the process, such as statistics approaches, systems approach and fuzzy mathematics approaches. Quality evaluation can be improved only by combining qualitative analysis with quantitative analysis effectively and combining empirical methods with humanistic methods.

\subsection{Function of Quality Evaluation is not Comprehensive}

The existing students' comprehensive evaluation attaches importance to outcome evaluation and ignore process evaluation; attaches importance to summarized evaluation, ignore period assessment; pay attention to output information evaluation by the object, but ignore that only by emphasizing input information can output information be evaluated, can process of information output be effectively assessed.

\section{Build Comprehensive Quality Evaluation Indicator System}

Students' comprehensive evaluation system is a kind of value judgment targeted at students' conduct in every aspect on campus. The key of accurate judgment is to design a scientific and reasonable comprehensive evaluation index system.

\subsection{Deign Principle of Index System}

Students' comprehensive evaluation index system must be able to play the role of guidance, examination, control and stimulating. It must be brief and to the point and convenient for operation. So design of comprehensive evaluation index system must adhere to the following principles: 
a) Principle of scientificity: As a practice of evaluating students' quality, comprehensive evaluation must be guided and regulated by scientific theories of education. Comprehensive evaluation index system is the embodiment of this guidance and regulation. The establishment of evaluation index system should not only embody the objective laws governing education but also conform to the laws of talents requirement to reflect the essential factors of comprehensive evaluation and their inner relationship.

b) Principle of independence: It is the basic requirement of establishing index system. Students' integrated quality consists of many factors. Each factor is relatively independent and separately reflects certain aspect of students. By observing change of every index in different periods, changing situation of students' mental attitude and learning attitude can be found.

c) Principle of guidance: Comprehensive evaluation system can play a guiding role for students if it can reflect the basic requirements for students in promoting quality education by university and guide many students to participate in the survey on activities. It can solve the essential problems of "do what" and "how to do" for students and define the goal and point of strength for students in quality education, which is to the advantage of students in making independent choice of development direction and growth approach under the restriction and guidance of relative rules of conduct to achieve ego development and self-management.

d) Principle of operability: Comprehensive evaluation index system, as a tool to judge students' quality, should not only make actual measurement of every aspect of students on campus but also be convenient for evaluator to operate in actual evaluation. This requires the index designed should: firstly, the index entries are concise and to the point, secondly, the information need to be collected for index is easy to observe and understand.

e) Principle of systematicity: Design of index should fully reflect the general condition of students' quality. Find index of main aspects from them which can reflect both direct effect and indirect effect to ensure integrality and credibility of comprehensive evaluation.

f) Principle of measurability: The index should have defined meaning and stratification, which is benefit for confirming index weighting and calculating data necessary for collection. The calculating method is easy.

g) Principle of combining qualitative index and quantitative index: Calculation by quantitative index can makes evaluation objective which is convenient for process by mathematical technique. Combination with qualitative index can make up for the lack of quantitative index to avoid partialness.

\subsection{Design Approach of Indicator System}

The subject of comprehensive quality evaluation is the student body. As to simple evaluation, indicator system can adopt level structure, which contains several coordinate indicators. Hierarchic structure, where relationship of administrative subordination exists between different layers, is used for the complex comprehensive evaluation. The students' comprehensive quality evaluation is connected with many complicated indicators and quality indicators of different layers have the distinct relationship of administrative subordination, so the university students' comprehensive quality evaluation indicator should adopt hierarchic structure according to the design principle of indicator system.

\subsection{Establishment of Indicator System}

In order to establish scientific university students' comprehensive quality evaluation system, the actual requirements for university students' qualities and abilities by the current society should be integrated into the indicator system in time to be the guide for quality education of students and self-development. Thus it is of great advantage to solving the employment problem of university graduates and self-development and more favorable to solving the problem fundamentally that higher education is out of line with social practices and improving the learning initiative and efficiency of students. 
Using scientific measurement and evaluation method according to evaluation model is the basis to ensure accuracy of quantitative evaluation results. Combining students' comprehensive evaluation practice of many universities, through analysis and discussion, the evaluation index system is defined and shown in Table I:

a) Moral education quality: Moral education quality is the most fundamental quality of university students. It include: political record, social responsibility, honest and trustworthy, civilization and orderliness, diligence, frugality and self-improvement, etc.

b) Intellectual education quality: Intellectual education quality is the basic quality of university students. It include: literacy programs, physical education and physical ability, etc.

Table 1 Comprehensive evaluation index system for university students

\begin{tabular}{|c|c|c|}
\hline First-level index & Second-level index & Main characteristics \\
\hline \multirow{5}{*}{ Moral education } & Political record & \multirow{5}{*}{$\begin{array}{l}\text { Advanced collectives and individuals, participation and } \\
\text { engagement in group activity, class attendance and } \\
\text { social practice condition, commendation by notice, } \\
\text { illegalities, breaching the principle, etc }\end{array}$} \\
\hline & Social responsibility & \\
\hline & Honest and trustworthy & \\
\hline & Civilization and orderliness & \\
\hline & Diligence, frugality and self-improvement & \\
\hline \multirow{2}{*}{$\begin{array}{l}\text { Intellectual } \\
\text { education }\end{array}$} & Literacy programs & \multirow{2}{*}{$\begin{array}{l}\text { General subject, special series of lecture, practical } \\
\text { course, PE class, physical ability test }\end{array}$} \\
\hline & Physical education and physical ability & \\
\hline \multirow{4}{*}{ Capability } & Autonomic learning & \multirow{4}{*}{$\begin{array}{l}\text { Career planning, curricula, social practice, academic } \\
\text { contests, scientific research, position in league and } \\
\text { students' organization and participation in society }\end{array}$} \\
\hline & Practice and innovation & \\
\hline & Organizational communication & \\
\hline & Social work & \\
\hline \multirow{3}{*}{$\begin{array}{l}\text { Personality } \\
\text { development }\end{array}$} & Innovation & \multirow{3}{*}{$\begin{array}{l}\text { Innovation and innovative undertaking competitions, } \\
\text { sports competitions, entertainment items, speaking and } \\
\text { debating, painting, calligraphy and photography, } \\
\text { results of other kinds of activities and recognition }\end{array}$} \\
\hline & Talent and skill & \\
\hline & others & \\
\hline
\end{tabular}

c) Competence quality: Competence quality is the important quality of university students. It include: autonomic learning, practice and innovation, organizational communication, social work, etc.

d) Personality development: Personality development is the necessary quality of university students. It include: innovation, talent and skill, etc.

\section{Effective Methods to Implement the Evaluation}

In order to establish scientific university students' comprehensive quality evaluation system, the actual requirements for university students' qualities and abilities by the current society should be integrated into the indicator system in time to be the guide for quality education of students and self-development. Thus it is of great advantage to solving the employment problem of university graduates and self-development and more favorable to solving the problem fundamentally that higher education is out of line with social practices and improving the learning initiative and efficiency of students. 


\subsection{Strengthen and Improve Moral Education, Increase the Effect of Moral Lessons Practically}

Make full use of the main channel of class, pay more attention to teaching of ideology and politics theory, use every possible means of teaching to improve the quality of education; teachers of professional courses should carry out moral education work combining their teaching of certain subject as well as impart knowledge and educate people; enhance the quality of full time tutors' team and attach great importance to after-class management; reinforce the theory research of ideological and political work and improve working mode and method of moral education from the aspect of theory and practice. Strengthen the daily education work, make great efforts to do theme education and characteristic education work and try to improve the pertinence and effectiveness of moral education.

\subsection{Establish a Team of High Competence Teachers to Ensure Enough Teachers' Resource for Full-scale Implementation of Quality-oriented Education}

Pay attention to and reinforce the professional ethics education for teachers; improve their political caliber and professional competence continuously to make them establish strong sense of social responsibility. Teachers should infect, guide and cultivate students with their words and deeds. They should impart knowledge and cultivate students. Besides, they should be a paragon of virtue and learning.

\subsection{Reinforce Educational Reform and Expand the Quality-oriented Education Platform}

Deepen the reform of teaching contents, teaching method and means aiming at overall development of students' comprehensive qualities. Design the comprehensive quality course reasonably. Students who study the Humanities and Social Science should take part of the natural science courses as elective course in order to upgrade their comprehensive qualities. Experimental education and practical teaching should be reinforced to improve the hands-on capability of the students. Strengthen and perfect establishment of intramural practice and off-campus practice and practical teaching base. Promote various skill events, which combine quality education with specialty construction closely, and expand quality education platform.

\subsection{Develop Scientific and Technological Cultural Activities, Cultivate Students’ Innovative Spirit}

According to the requirements of improving students' comprehensive qualities, innovate boldly the mode and contents of scientific and technological cultural activities, elaborate and develop appealing activities with novel form; develop the integrated activities to expand university students' qualities, including "Culture and Art Festival", "Scientific and Technological Cultural Festival" as well as "Extracurricular Activities". Take the scientific and technological cultural activities as the important approach to improve students' comprehensive qualities.

\subsection{Strengthen Social Practice Effectively, Strive to Improve Practical Abilities}

Firmly foster the thought that practice can cultivate people and take practical activities as the important way to improve students' comprehensive qualities. Organize students to carry out social practice survey, voluntary service and activities for public good in a deep-going way and guide them learn to be and learn to do. 


\subsection{Perfect examination and evaluation system, implement comprehensive quality evaluation system}

Scientific evaluation system is of advantage to evaluation of students' all-around development and improvement. So it plays an important role in controlling, adjusting and improving the teaching and learning activities. It is necessary to perfect the examination evaluation system and implement comprehensive quality evaluation system.

\section{Conclusions}

In conclusion, as the students' evaluation system used in universities, students' comprehensive quality evaluation plays an important role in arousing students' active learning initiatives, advancing self comprehensive qualities in an all-round way and cultivating innovative spirit and practical capabilities. Only by continuous practices and explorations, perfecting evaluation system and establishing a set of students' comprehensive qualities evaluation methods suitable for actual conditions of the university, can we do students' comprehensive qualities evaluation well, push ahead quality-oriented education, improve comprehensive qualities of university students and realize talent-cultivation.

\section{Acknowledgment}

The research was sponsored by the key scientific and technological project of the Education Department of Henan Province. We would like to thank the referee for his/her careful reading and helpful suggestions.

\section{References}

[1] Frank R.Giordano, Maurice D.Weir, William P.Fox, A First Course in Mathematical Modeling, Thomson, 2001.

[2] Jiang Qiyuan, Mathematical Model(in Chinese), Higher Education Press, 2003.

[3] William F.Lucas, Modules in Applied Mathematics.Vol.3:Discrete and System Models, Springer-Verlag, 1996.

[4] Tang Huanwen, Mathematical Model: An instroduction(in Chinese). Higher Education Press, 2002.

[5] Zhou Wei, Gao Chuan, "Modeling of Students'Comprehensive Assessment System Based on UML(in Chinese)", Computer and Modernization, no.10, pp.147-153, October 2009.

[6] Zhang Yun, "Reform of Comprehensive evaluation index system for University Students(in Chinese)", Journal of South China Normal University(Social Science Edition), no.3, pp. 141-143, June 2009.

[7] He Yongqiang, "Study on the Comprehensive Evaluation System for University Students ,"TEIN2010, 2010..

[8] Huang Tiyun, Management Information System(in Chinese), Higher Education Press, 2000.

[9] Liu Zhenhua, The Design and Implementation of Web-based Integrated Student Management Information System(in Chinese), CHINA EDUCATION INFO, No.12, 2006, pp. 47-48.

[10] Wang Shan, An Introduction to Database Systems(in Chinese), Higher Education Press, 2006.

[11] Paul, Allen, Component-Based Development for Enterprise Systems, Cambridge Universicy Press, 2003. 